\title{
Role of human capital in efficiency increases: evidence from a data envelopment analysis of rubber smallholdings in Gampaha district
}

\author{
Hansanamali Kumarasinghe, Jagath C Edirisinghe and M A Buddhika Patalee \\ * Faculty of Agriculture \& Plantation Management, Wayamba University of Sri Lanka, \\ Makandura, Gonawila (NWP), Sri Lanka
}

Received 19 April 2012

\begin{abstract}
This study was carried out to analyze the present level of technical efficiency of rubber smallholders in Gampaha district and primary data were collected from 100 smallholder rubber farmers. Data Envelopment Analysis (DEA) was utilized to estimate technical efficiency levels. A double censoring Tobit model was estimated to assess factors affecting technical efficiency. Farmer specific and tapper specific factors were considered as covariates in the Tobit model. Findings reveal that, levels of human capital of owner farmers as well as latex extractors account for variations in technical efficiency levels. This highlights the importance of directing extension services not only towards the owner farmers, but also towards hired latex extractors to reap benefits of the present price hikes in the rubber sector.
\end{abstract}

Key words: data envelopment analysis, rubber smallholders, technical efficiency, Tobit model

\section{Introduction}

The spiraling prices of petroleum and its consequent impact on production cost of synthetic rubber has further impressed the long-term prospects for natural rubber (Sivakumaran, 2010). In next six years, the country will need around 150,000 metric tons of rubber per year just to meet the escalating demand from local rubber based industries. Considering the global demand for raw rubber exports, ideally 200,000 metric tons of natural rubber is to be produced per annum by 2016 in Sri Lanka (Rodrigo et al., 2011). The three main strategies to meet this increasing demand may be replanting existing stands with modern high-yielding clones, increasing area of new plantings and enhancing yield productivity of existing stands of mature rubber lands (Sivakumaran, 2010). In the short term, concentrating on the latter is prudent. In attempting to enhance the productivity 
of existing lands, one crucial aspect is increasing efficiency with which farmers use their inputs in obtaining outputs. In literature, this is measured in terms of technical efficiency and a vast body of literature surrounds techniques and applications of technical efficiency analysis (for example, see Bravo-Ureta and Pinheiro (1993) and MurilloZamorano, 2004).

One important aspect of studies on technical efficiency analyses is the role of human capital in determining levels of efficiency of farmers. In most cases, the level of human capital is measured in terms of farmer education, experience and contacts with extension service. After reviewing 30 studies from 14 different developing countries, BravoUreta and Pinheiro (1993) report that these variables show a positive and statistically significant impact on technical efficiency. Therefore, there is no doubt that human capital play a vital role in technical efficiency increases.

Extension is the major tool that is used to develop human capital in smallholder farmers. In most instances, extension efforts are directed towards owner farmers with the intension of increasing efficiency in smallholder rubber cultivation. Directing extension efforts towards owner farmers is prudent as they are the decision makers with respect to the classical questions in production economics; what to produce, how to produce and how much to produce. However, even with small- holder farmers, the main activity in rubber cultivation is carried out by hired labor. As extension service is usually government supported and runs on scarce funding available to the government agencies that provide extension, it is prudent to ask, where should the extension service be directed to have the most desired outcome? However, previous studies on technical as well as allocative efficiency of rubber cultivation (Edirisinghe, et al. 2010, Bogahawatte, 1999 and Talgaswatta, 1995) have not inquired into this issue. Therefore, this study looks at the role of human capital of owner farmers as well as latex extractors in improving technical efficiency in smallholder rubber cultivation.

\section{Methodology \\ Sample selection}

This study covered rubber smallholders in all Rubber Development Officer's (RDO) divisions in Gampaha district; Weliveriya, Meerigama, Minuwangoda, Dompe, Urapola, Thihariya, Pasyala, Radawana and Pepiliyawala. A multi stage sampling scheme was used to obtain the sample. Three to five Grama Niladari (GN) divisions were selected from each RDO division and individuals were selected randomly from each selected GN division. Total sample size was restricted to 100 considering the limitations on expenses and time. 


\section{Data collection}

Data were cross sectional in nature, and they were collected through a pre-tested questionnaire, during the month May 2011 via. face to face interviews and telephone conversations. Data included information on production and socio economic characteristics of smallholder rubber farmers as well as latex extractors.

\section{Analytical method}

First, an efficiency analysis was carried out. Then, estimated efficiency scores were related to socio economic characteristics of owner farmers as well as latex extractors in order to understand what determines efficiency. This two stage estimation is criticized in literature because of endogeneity bias it may create. The argument for this criticism is that although it is assumed in the first stage that estimates of technical efficiency are independently distributed, in the second stage these efficiency estimates are assumed to have a functional relationship with explanatory variables. However, Barnes (2006) notes that even in the alternative one stage procedure, the Stochastic Frontier analysis, also suffers from bias due to assumptions regarding adopting a functional form in estimation (Barnes, 2006).

Efficiency analysis entails an estimation of an efficiency frontier. To estimate efficiency frontiers, many methods are available. These can be "Classical
Stochastic Frontiers", "Bayesian Stochastic Frontiers" or "Data Envelopment Analysis (DEA)". The Classical Stochastic Frontier Analysis differs from the Bayesian by the statistical paradigms. However, DEA, which is also a classical technique, differs in terms of assumptions about the data generation process (Balcombe, et al., 2006). There are merits and demerits of all these methods. For example, stochastic frontier analysis imposes explicit functional form and distributional assumptions on data. Non parametric methods such as DEA do not impose any assumptions about the functional forms and therefore, is not subject to the problems of assuming an underlying distribution for the error term (Kaliba, 2004). However, it has the limitation of not having a random error term. There is no universal method to choose between the two popular methods of estimation of technical efficiency (i.e. DEA and SFA). Those studies that compare DEA and SFA in estimating technical efficiency report that the choice of the method used does not have much influence on the results, especially in ranking of firms on efficiency (Coelli and Perelman, 1999; Resti, 1997; Iráizoz et al., 2003).

DEA involves the use of linear programming methods to construct a non-parametric frontier over the data and calculate efficiencies relative to this surface. Firms that operate on the frontier are technically efficient and the 
Hansanamali Kumarasinghe et al.

firms beneath the frontier are technically inefficient. Technical efficiency of one firm is measured relative to the most efficient firm in the sample, and it can be defined as the capacity of an economic unit to produce the maximum possible output from a given bundle of inputs and a given technology. Technical inefficiency is the amount by which outputs could be increased without requiring extra inputs. The DEA solves a linear programming problem given as;

$\operatorname{Max} \varphi, \lambda \quad \varphi$

$$
\begin{array}{ll}
\text { Subject to } & \mathrm{X}_{\mathrm{k}}-\mathrm{X} \lambda \geq 0 \\
& -\varphi \mathrm{y}_{\mathrm{k}}+\mathrm{Y} \lambda \geq 0 \\
& \lambda \geq 0
\end{array}
$$

Where, $\mathrm{X}$ represents the input matrix, $\mathrm{Y}$ represents the output matrix and $\lambda$ is a $N$ $\mathrm{x} 1$ vector of constants. $\mathrm{x}_{\mathrm{k}}$ is the input vector of the $\mathrm{k}^{\text {th }}$ farmer and $\mathrm{y}_{\mathrm{k}}$ is the output of the $\mathrm{k}^{\text {th }}$ farmer. The optimal solution to this problem $\left(\varphi^{*}\right)$ represents the proportional increase in output that could be achieved by the $\mathrm{k}^{\text {th }}$ farmer, while holding the input levels constant. This DEA is an output oriented model, where, $\varphi^{*}$ is the technical efficiency score (Coelli et al., 2005).

Data Envelopment Analysis Programme (DEAP) version 2.1 was used to construct the piece-wise linear programme given above (Coelli, 1996). Output oriented Constant Returns to Scale model (CRS) was used in estimating of technical efficiency using the production data; output
(kg/Year),total number of tappable trees, the fertilizer amount applied (kg/Year), total cost for chemicals (Rs./Year) and the total number of tappers. Output oriented CRS model is an appropriate specification since most farmers are interested in expanding output given their inputs. However, when CRS is assumed, the same value is given for the estimated technical efficiency score (Coelli et al., 2005).

The censored regression (Tobit) model In DEA, a farmer on the efficient frontier is given a score of one and any farmer that lies below the efficient frontier is given a score between zero and one. Thus, a double censoring Tobit model is applicable (Kaliba, 2004). Tobit models are appropriate because of two reasons. First, the calculated relative productive efficiency measures are censored between zero and one or in other words it can be scaled to be between zero and $100 \%$. Second, the Tobit model enables calculation of both the marginal effect of the explanatory variable on the efficiency measure and the probability of improvement for inefficient farms. Because the estimated efficiency measures are bounded between zero and one, a two limit (double bounded) Tobit is suitable (Greene, 1993)

$$
\begin{gathered}
T E=y^{*} \text { for } 0 \leq y^{*} \leq 1 \\
T E=0 \text { for } y^{*}<0 \\
T E=1 \text { for } y^{*}>1 \\
y^{*}=\beta^{\prime} X+u \text { for } 0 \leq y^{*} \leq 1
\end{gathered}
$$


Where $y^{*}$ is the inefficiency score, TE is the technical efficiency score, $\beta$ is the parameter vector and $\mathrm{u}$ a $N\left(0, \sigma^{2}\right)$ distributed error term. The vector of regressors, X, includes, Smallholder's age (Years), Smallholder's gender (Dummy: $\quad$ Male $=1, \quad$ Female $=0$ ), smallholder's education (Years), membership in a rubber society (Dummy: Yes $=1, \mathrm{No}=0$ ), number of extension agent visits, tapper's age (Years), tapper's education (Years) and dummy variable representing use of hired labor (Hired $=1$, otherwise 0 ). These variables included in the Tobit model were carefully selected. Because our interest is to compare the impact of levels of human capital of owners as well as latex extractors on efficiency, two variables were incorporated (Tappers age and education) related to levels of human capital of latex extractors apart from those that relate to human capital of owner farmers. The Tobit model was estimated using STATA 11 computer software.

\section{Results and Discussion}

Table 1 depicts the summary statistics related to variables used in DEA and obtained technical efficiencies are given in Table 2. Results revealed that smallholders' technical efficiency levels varied from $8 \%$ to $100 \%$ and $77 \%$ of farmers ranged between $20-70 \%$ of technical efficiency levels. The mean technical efficiency of rubber smallholding sector in Gampaha district was found to be $49.8 \%$, which indicates that the output could be increased by $50.2 \%$ if all farmers achieved full technical efficiency (Table 2). This value is considerably less than what previous studies reported for other districts in the country (Edirisinghe, et al., 2010; Talgaswatta, 1995), but these researches concentrated on traditional rubber growing districts such as Kalutara, Kegalle and Ratnapura. Considering the mean level of output recorded in the present sample (1100 $\mathrm{kg} / \mathrm{ha} /$ year), increases that could be made if full efficiency is reached is substantial. As these increases in output could be made without any change in the cost structure of farmers, the impact on farmer income will be invaluable. On the other hand, not using scarce resources that farmers own to maximum is a waste of such resources in a time where opportunity cost of resources (such as land) is extremely high.

Table 3 reports results of the Tobit regression where farmer specific variables are related to the estimated efficiency levels in order to identify determinants of technical efficiency. 
Hansanamali Kumarasinghe et al.

Table 1. Summary statistics for variables used in the analysis

\begin{tabular}{lrrr}
\hline Variable & Sample mean & Min value & Max value \\
\hline Output (kg/year) & 1100 & 135 & 6950 \\
Tappable trees/farm & 380 & 45 & 1450 \\
Fertilizer (kg/year) & 117 & 0 & 720 \\
Chemical cost (Rs/year) & 2401 & 0 & 20130 \\
Total no. of tappers & 1.5 & 1 & 5 \\
Farmer age (years) & 56.94 & 28 & 81 \\
Farmer education (years) & 11.33 & 0 & 18 \\
Extractor age (years) & 52.27 & 28 & 88 \\
Extractor education (years) & 8.2 & 0 & 13 \\
Extension visits & 2.84 & 0 & 12 \\
$\%$ of male farmers in the sample & & 73 & \\
$\%$ of society members in the sample & & 43 & \\
$\mathrm{~N}$ & & 100 & \\
\hline
\end{tabular}

Table 2. Distribution of technical efficiencies

\begin{tabular}{cc}
\hline No. of smallholders & Technical efficiency $(\%)$ \\
\hline 1 & $0-10$ \\
6 & $11-20$ \\
16 & $21-30$ \\
17 & $31-40$ \\
14 & $41-50$ \\
16 & $51-60$ \\
14 & $61-70$ \\
7 & $71-80$ \\
1 & $81-90$ \\
8 & $91-100$ \\
\hline
\end{tabular}

In the Tobit regression, a positive variable, which is the technical coefficient implies that any increase in efficiency. Similarly a negative the value of a variable would lead to an coefficient implies that any increase in increase in the level of the latent the value of the variable would lead to a 
decrease in the level efficiency. Therefore, from the point of view of reducing inefficiency in rubber cultivation, variables with positive coefficients are of interest. We find that all variables except membership of the rubber society report positive signs. The coefficients reported in the Tobit regression relates to the latent variable $\left(y^{*}\right)$ and not the actual technical efficiency itself. This is of no interest as the latent variable is unobserved. The slope coefficient for the observed technical efficiency (TE) estimates can be obtained from

$$
\frac{\partial E(T E \mid X)}{\partial X}=\beta \times \operatorname{Prob}\left[0<y_{i}^{*}<1\right]
$$

Where $\beta$ is the coefficient from Tobit regression and $\operatorname{Prob}\left[0<\mathrm{y}_{\mathrm{i}}^{*}<1\right]$ is the probability of the latent variable $\left(\mathrm{y}^{*}\right)$ falling between the two censoring limits. The marginal effects obtained in this manner are reported in Table 4.

Our interest in this research was to evaluate the impact of human capital of the owner farmer as well as the latex extractor (labor) on efficiency. The regression included two key variables representing human capital: Education and Age (experience). Results show positive and significant coefficients in education level of owner farmers as well as the latex extractors. The two marginal effects of farmer and labour education levels are almost similar. Thus, level of human capital of both farmer and the labourer is equally important in achieving high efficiency. Further, age (which represent experience) show statistical significance in the case of labour, but fail to show significance in the case of farmer. Age may represent experience in latex extraction in the labour force. This statistical significance is very much true because in the case of rubber cultivation, efficiency may well lie in the manner latex is extracted. Unskilled latex extraction leads to low yields at present as well as in future as barks of trees get damaged in the long run. Because a rubber plantation has approximately a 30 year economic life span, proper latex extraction will lead to efficient production in the long run. However, the negative and significant sign of the dummy variable for hired labour indicate that still, farmers who own and operate their rubber lands are more efficient than farmers who own but use labour in operation. This is as expected. Variable relating to extension effort, which was introduced in to the model to capture the effect of extension effort on efficiency does not show statistical significance. However, the expected positive sign was observed. 
Table 3. Results of Tobit model

\begin{tabular}{llrrrr}
\hline Variable & Coef. & Std. Err. & P> $|\mathbf{t}|$ & \multicolumn{2}{c}{ [95\% C.I.] } \\
\hline Farmer age & 0.0008 & 0.0021 & 0.7020 & -0.0034 & 0.0050 \\
Farmer education & $0.0209 * *$ & 0.0122 & 0.0890 & -0.0033 & 0.0451 \\
Extension visits & 0.0048 & 0.0085 & 0.5710 & -0.0120 & 0.0216 \\
Labour age & $0.0060^{*}$ & 0.0021 & 0.0060 & 0.0018 & 0.0102 \\
Labour education & $0.0154 * *$ & 0.0088 & 0.0850 & -0.0022 & 0.0329 \\
Farmer gender & 0.0036 & 0.0540 & 0.9470 & -0.1036 & 0.1108 \\
Society membership & -0.0668 & 0.0460 & 0.1500 & -0.1582 & 0.0246 \\
Hired dummy & $-0.1160 *$ & 0.0554 & 0.0390 & -0.2261 & -0.0059 \\
Constant & -0.1259 & 0.2345 & 0.5930 & -0.5917 & 0.3399 \\
Prob > F & 0.0295 & & & & \\
Log pseudo likelihood & -182.01 & & & & \\
\hline
\end{tabular}

*Significant at 5 percent level **Significant at 10 percent level

Table 4. Calculated slopes of coefficient of the Tobit model

\begin{tabular}{llrrrr}
\hline Variable & $\mathbf{d y} / \mathbf{d x}$ & $\begin{array}{r}\text { Std. } \\
\text { Err. }\end{array}$ & $\mathbf{P}>|\mathbf{z}|$ & \multicolumn{2}{c}{ [95\% C.I.] } \\
\hline Farmer age & 0.0008 & 0.0020 & 0.7010 & -0.0032 & 0.0048 \\
Farmer education & $0.0201^{* *}$ & 0.0115 & 0.0810 & -0.0025 & 0.0426 \\
Extension visits & 0.0046 & 0.0081 & 0.5690 & -0.0113 & 0.0205 \\
Labour age & $0.0058^{*}$ & 0.0020 & 0.0040 & 0.0019 & 0.0096 \\
Labour education & $0.0147^{* *}$ & 0.0084 & 0.0800 & -0.0018 & 0.0313 \\
Farmer gender & 0.0035 & 0.0518 & 0.9470 & -0.0981 & 0.1050 \\
Society membership & -0.0641 & 0.0439 & 0.1450 & -0.1502 & 0.0220 \\
Hired dummy & $-0.1113^{*}$ & 0.0527 & 0.0350 & -0.2146 & -0.0080 \\
\hline
\end{tabular}

*Significant at 5 percent level **Significant at 10 percent level 


\section{Conclusions}

Results obtained from DEA showed that the average technical efficiency of rubber smallholding sector in Gampaha district was $49.8 \%$. This indicates that there are possibilities for further increases in output by $50.2 \%$ without any increase in levels of inputs. Increases in efficiency therefore will have a marked impact on smallholder income in the context of present hikes in natural rubber prices.

Higher and similar size of the coefficient for education of both smallholder as well as the tapper provides important insight about the importance of improved human capital in increasing efficiency levels and hence farmer income. In previous studies, only factors specific to the owner farmer has been considered in providing policy implications on how to increase efficiency. This paper deviates from the typical, and have included factors specific to laborers, whom is an important entity in rubber production. Findings reveal that developing human capital in the tapper community is also important as developing the farmer community. The present extension effort, which usually targets owners of rubber smallholdings, should be directed towards the tapper community as well to reap benefits of higher prices as well as full potential of high yielding clones available.

\section{Acknowledgements}

Authors would like to express their gratitude to all the RDO officers of Gampaha district and the respondents of the survey.

\section{References}

Balcombe, K, Fraser, I and Kim, J H (2006). Estimating technical efficiency of Australian dairy farms using alternative frontier methodologies. Applied Economics 38, 2221-2236.

Barnes, A P (2006). Does multifunctionality affect technical efficiency? A non-parametric analysis of the Scottish dairy industry. Journal of Environmental Management 80, 287294.

Bogahawatte, C (1999). Efficiency of smallholder rubber production in Sri Lanka: A case study in Kegalle, Ratnapura, Kalutara and Gampaha districts. Sri Lankan Journal of Agricultural Sciences 36, 42-52.

Bravo-Ureta, B E and Pinheiro, A E (1993). Efficiency analysis of developing country agriculture: A review of the frontier function literature. Agricultural and Resource Economics Review 22.

Coelli, T J, Rao, D S P, O'Donnel, C J and Battese, G E (2005). An Introduction to Efficiency and Productivity Analysis. $2^{\text {nd }}$ ed. USA, Springer Science and Business Media.

Coelli, T J (1996). A guide to DEAP version 2.1: A data envelopment analysis (Computer) programme. CEPA orking paper No 8/96, Department of Econometrics, University of New England. 
Hansanamali Kumarasinghe et al.

Coelli, T and Perleman, S (1999). A comparison of parametric and nonparametric distance functions: With application to European railways. European Journal of Operational Research 117, 326-339.

Edirisinghe, J, Wijesuriya, $\mathrm{W}$ and Bogahawatte, C (2010). Profit efficiency of smallholder rubber farmers in Kegalle, Kalutara and Ratnapura districts. Journal of the Rubber Research Institute of Sri Lanka 90, 64-78.

Greene, W H (1993). Econometric Analysis. Prentice Hall, New Jersey, USA.

Iráizoz, B, Rapún, M and Zabaleta, I (2003). Assessing the technical efficiency of horticultural production in Navarra, Spain. Agricultural Systems 78, 387-403.

Kaliba, A R (2004). Technical efficiency of smallholder dairy farms in central Tanzania. Quarterly Journal of International Agriculture 43, 39-55.

Murillo-Zamorano, L R (2004). Economic efficiency and frontier techniques. Journal of Economic Surveys 18, 33-77.

Rodrigo, L and Munasinghe, E (2011). Rubber tree should not only be for latex but for carbon trading too! Available from http://www.Sundaytimes.lk/ 110710/Business Times/bt08. html (Accessed 14 July 2011).

Resti, Andrea (1997). Evaluating the costefficiency of the Italian Banking System: What can be learned from the joint application of parametric and nonparametric techniques. Journal of Banking \& Finance 21, 221-250.

Sivakumaran, S (2010). Strategies for enhancing natural rubber production to meet increasing global demand. Journal of the National Institute of Plantation Management 24 (2), 1-19.

Talgaswatta, H (1995). Technical efficiency of rubber production in Sri Lanka: Frontier production function approach. PhD Thesis, Lincoln University, New Zealand.

Address for correspondence: Dr Jagath Edirisinghe, Department of Agribusiness Management, Faculty of Agriculture and Plantation Management, Wayamba University of Sri Lanka, Makandura, Gonavila (NWP)

e-mail: jagathed@yahoo.com 